\title{
CRYOGENIC FUEL STORAGE MODELLING AND OPTIMISATION FOR AIRCRAFT APPLICATIONS
}

\author{
Pavlos Rompokos \\ Cranfield University \\ Cranfield, United Kingdom
}

\author{
Andrew Rolt \\ Cranfield University \\ Cranfield, United Kingdom
}

\author{
Devaiah Nalianda \\ Cranfield University \\ Cranfield, United Kingdom
}

\author{
Thierry Sibilli \\ SAFRAN S.A. \\ Châteaufort, France
}

\author{
Claire Benson \\ London South Bank University \\ London, United Kingdom
}

\section{ABSTRACT}

Designing commercial aircraft to use liquid hydrogen $\left(\mathrm{LH}_{2}\right)$ is one way to substantially reduce their life-cycle $\mathrm{CO}_{2}$ emissions. The merits of hydrogen as an aviation fuel have long been recognized, however, the handling of a cryogenic fuel adds complexity to aircraft and engine systems, operations, maintenance and storage. The fuel tanks could account for 8$10 \%$ of an aircraft's operating empty weight, so designing them for the least added weight is of high significance.

This paper describes the heat transfer model developed in the EU Horizon 2020 project that is used to predict heat ingress to a cylindrical tank with hemispherical end caps with external foam insulation. It accounts for heat transfer according to the state of the tank contents, the insulation material properties, the environment, and the dimensions of the tank. The model also estimates the rate of pressure change according to the state of the fuel and the rate at which fuel is withdrawn from the tank. In addition, a methodology is presented, that allows for tank sizing taking into consideration the requirements of a design flight mission, the maximum pressure developed, and the fuel evaporated.

Finally, the study demonstrates how to select optimal insulation material and thickness to provide the lightest design for the cases where no gaseous hydrogen is extracted, and where some hydrogen gas is extracted during cruise, the latter giving gravimetric efficiencies as high as $74 \%$.

Keywords: Hydrogen, Alternative Energy Sources, Aerospace Applications, Heat Transfer

\begin{tabular}{lcl}
\multicolumn{4}{l}{ NOMENCLATURE } \\
$\mathrm{C}_{\mathrm{p}}$ & $(\mathrm{J} / \mathrm{kg} \cdot \mathrm{K})$ & Specific heat capacity \\
$\mathrm{D}_{0}$ & $(\mathrm{~m})$ & Internal tank diameter \\
$\mathrm{e}_{\mathrm{w}}$ & $(-)$ & Weld efficiency \\
$\mathrm{FoS}$ & $(-)$ & Factor of Safety for pressure \\
$\mathrm{GH}_{2}$ & & Gaseous Hydrogen \\
$\mathrm{h}$ & $(\mathrm{J} / \mathrm{kg})$ & Enthalpy \\
$\mathrm{h}_{\mathrm{lg}}$ & $(\mathrm{J} / \mathrm{kg})$ & Latent heat of vaporization \\
$\mathrm{k}$ & $(\mathrm{W} / \mathrm{m} \cdot \mathrm{K})$ & Thermal conductivity \\
$\mathrm{LH}_{2}$ & & Liquid Hydrogen \\
$\mathrm{M}$ & $(\mathrm{kg})$ & Mass \\
$\mathrm{m}$ & $(\mathrm{kg} / \mathrm{s})$ & Mass flow rate \\
$\mathrm{mix}$ & & Mixture \\
$\mathrm{P}$ & $(\mathrm{Pa})$ & Pressure \\
$\mathrm{Q}$ & $(\mathrm{W})$ & Thermal power \\
$\mathrm{s}$ & $(\mathrm{J} / \mathrm{kg} \cdot \mathrm{K})$ & Entropy \\
$\mathrm{T}$ & $(\mathrm{K})$ & Temperature \\
$\mathrm{t}_{\mathrm{w}}$ & $(\mathrm{m})$ & Wall thickness \\
$\mathrm{v}$ & $(\mathrm{Pa} \cdot \mathrm{s})$ & Kinematic viscosity \\
$\mathrm{V}$ & $\left(\mathrm{m}^{3}\right)$ & Volume \\
$\mathrm{W}$ & $(\mathrm{W})$ & Additional thermal power input \\
$\mathrm{x}$ & $(-)$ & Mixture Quality \\
$\Delta \mathrm{p}$ & $(\mathrm{Pa})$ & Maximum allowable pressure \\
$\eta_{\text {tank }}$ & $(-)$ & Tank gravimetric efficiency \\
$\rho$ & $\left(\mathrm{kg} / \mathrm{m}^{3}\right)$ & Density \\
$\sigma_{\alpha}$ & $(\mathrm{Pa})$ & Maximum allowable stress \\
$\Phi$ & $\left(\mathrm{Pa} \cdot \mathrm{m}^{3} / \mathrm{J}\right)$ & Energy Derivative \\
& &
\end{tabular}




\section{INTRODUCTION}

Hydrogen has long been considered as an aviation fuel due to its high heating value and its potential for zero in-flight $\mathrm{CO}_{2}$ emissions. However, apart from some very short-range aircraft applications, liquefaction of hydrogen is required to store it at maximum density and to minimise storage volume and weight.

For the same energy content, liquid hydrogen $\left(\mathrm{LH}_{2}\right)$ saves almost two-thirds of fuel mass compared to Jet A, potentially reducing aircraft take-off weight if the tanks can have high gravimetric efficiency (the ratio of the usable hydrogen mass to the mass of a full fuel tank). However, even when the $\mathrm{LH}_{2}$ is stored at temperatures as low as $20 \mathrm{~K}$, the tanks will still need a volume four times greater than for Jet A, implying larger and heavier airframes.

A significant $\mathrm{LH}_{2}$ tank implementation for jet aircraft dates back to the $1950 \mathrm{~s}$, when the NACA was considering using hydrogen as fuel to power high altitude subsonic and supersonic military aircraft [1], and it modified and tested a Martin B-57 Canberra aircraft to operate with $\mathrm{LH}_{2}$ on one of the engines [2]. Two tanks were integrated on the wing tips, one to house the $\mathrm{LH}_{2}$ and the other to store helium gas, which was used as a pressurising medium for the $\mathrm{LH}_{2}$ tank. In late 1980s Tupolev modified a Tu 154 to operate with one of its three engines running on liquefied natural gas or $\mathrm{LH}_{2}$ and mounted an $18 \mathrm{~m}^{3}$ cylindrical tank inside the aft end of the pressurised fuselage [3]. The latest relatively large scale demonstration was made by Boeing in 2012, when the Phantom Eye unmanned aircraft was designed and tested. The fuselage was built around two large spherical $\mathrm{LH}_{2}$ tanks that supplied a pair of piston engines [4].

In parallel with the experimental applications, several studies have included preliminary tank designs. Brewer [5], [6] thoroughly discussed the materials used for the tank wall, the wall configuration as well as the tank shape and positioning for a particular long range application. The studies [7], [8] used heat transfer principles to account for heat transfer effects, [9] - [11] used the heat transfer to estimate the rate of pressure change inside the tank and [8], [10], [11] demonstrated the effects of tank geometry on the heat transfer.

This paper discusses tank design integration and safety aspects and describes the model and methodology developed to optimally size a $\mathrm{LH}_{2}$ tank based on aircraft requirements and the varying conditions throughout a design mission. Effects such as temperature stratification, tank contents mixing and gaseous hydrogen $\left(\mathrm{GH}_{2}\right)$ extraction or venting are also taken into account in the estimation of $\mathrm{LH}_{2}$ pressure fluctuations. The model was conceived in the context of European Union's Horizon 2020 ENABLEH2 project and will be used in an integrated framework that allows for the preliminary design of hydrogen-powered aircraft.

\section{SAFE $\mathrm{LH}_{2}$ FUEL SYSTEM AND TANK DESIGNS}

Hydrogen behaves and burns very differently to Jet A and other hydrocarbon fuels. It has high permeability and low viscosity, so small leaks are more common than for other fuels and must be considered likely [12]. The gas is more buoyant than air, so it disperses upwards and can become trapped in overhead voids. It also has a wide range of flammability in air, c. $4-75 \%$ by volume, compared with $0.5-5 \%$ for kerosene, which only burns when its liquid surface is above the flash point temperature (typically $38^{\circ} \mathrm{C}$ at sea level) [12]. However, hydrogen flames only have about half of the radiative output of hydrocarbon flames [13], so thermal damage from a fire may be more limited. Cryogenic $\mathrm{LH}_{2}$ also adds hazards like cold burns, and with $\mathrm{LH}_{2}$ stored as low as $20 \mathrm{~K}$, oxygen could condense on fuel system components, increasing ignition hazards.

Hydrogen-fuelled aircraft will be held to safety standards that match or exceed those for kerosene-fuelled aircraft. Safety considerations affect not only the design of aircraft fuel systems and the $\mathrm{LH}_{2}$ storage tanks, but also the supporting airport infrastructure and fuelling operations. An analysis of the safety needs was made at the start of the ENABLEH2 project [14].

The fuel system must prevent contact of the $\mathrm{LH}_{2}$ with air, which requires pressurised tanks with walls resistant to hydrogen permeation. It is uneconomic and unsustainable to use helium gas for routine pressurisation, so the temperature of the $\mathrm{LH}_{2}$ will determine the pressure in the tanks. Adequate thermal insulation must be provided to limit heat transfer to the fuel and avoid excessive pressure build-up in the tanks, or the need to vent gas in normal operation. A spherical double-wall vacuum-insulated tank with multi-layer insulation offers the lowest boil-off rate and will be the lightest solution for tanks required to store $\mathrm{LH}_{2}$ for long periods [15]. However, provided their durability can be established, single-wall designs with rigid-cell polyurethane or polyvinylchloride foam insulation will offer lighter solutions for large tanks that do not need to provide long-term storage.

The wings of commercial aircraft having conventional 'tube and wing' architecture do not provide sufficient volume to store the $\mathrm{LH}_{2}$, and external tanks would significantly increase drag, so tanks generally need to be placed inside the fuselage. Fig. 1 illustrates a wide variety of aircraft with $\mathrm{LH}_{2}$ tanks shown schematically in various positions. The tanks do not necessarily need to be cylindrical. A short-range aircraft may have all its tanks placed aft of the passenger cabin, provided that, as fuel is consumed, the changes in the aircraft's centre of gravity would be acceptable. However, a long-range aircraft with heavier fuel load must have tanks more evenly balanced about its centre of gravity. These tanks may be located either above or below the passenger cabin, or both forward and aft of it. Also, if the wing roots are enlarged, tanks could extend into them. Blended Wing Body and other novel airframes may offer further spaces for the fuel tanks. The pros and cons of different configurations are further discussed in [16]. Equally significant for safety is the positioning of tanks in relation to other aircraft systems. The longer the fuel lines, and more importantly, the more joints there are in them, the greater the likelihood of leaks. Also placing any fuel lines in areas subject to high stress or where they could be more susceptible to foreign object damage, has to be carefully considered when siting the tanks. Long cylindrical tanks will probably need to be subdivided into smaller tanks to reduce instability in pitch or roll as the fuel in half-full tanks migrates 
from one end to the other. Tanks must not be placed where there is danger that an uncontained engine failure could puncture them. Larger diameter tanks that minimise surface area to volume ratio can save on thermal insulation. Also, where they utilise the full diameter of the fuselage, they might be integrated into the airframe structure [6], [17] though this could make them more at risk of rupture in certain crash scenarios.

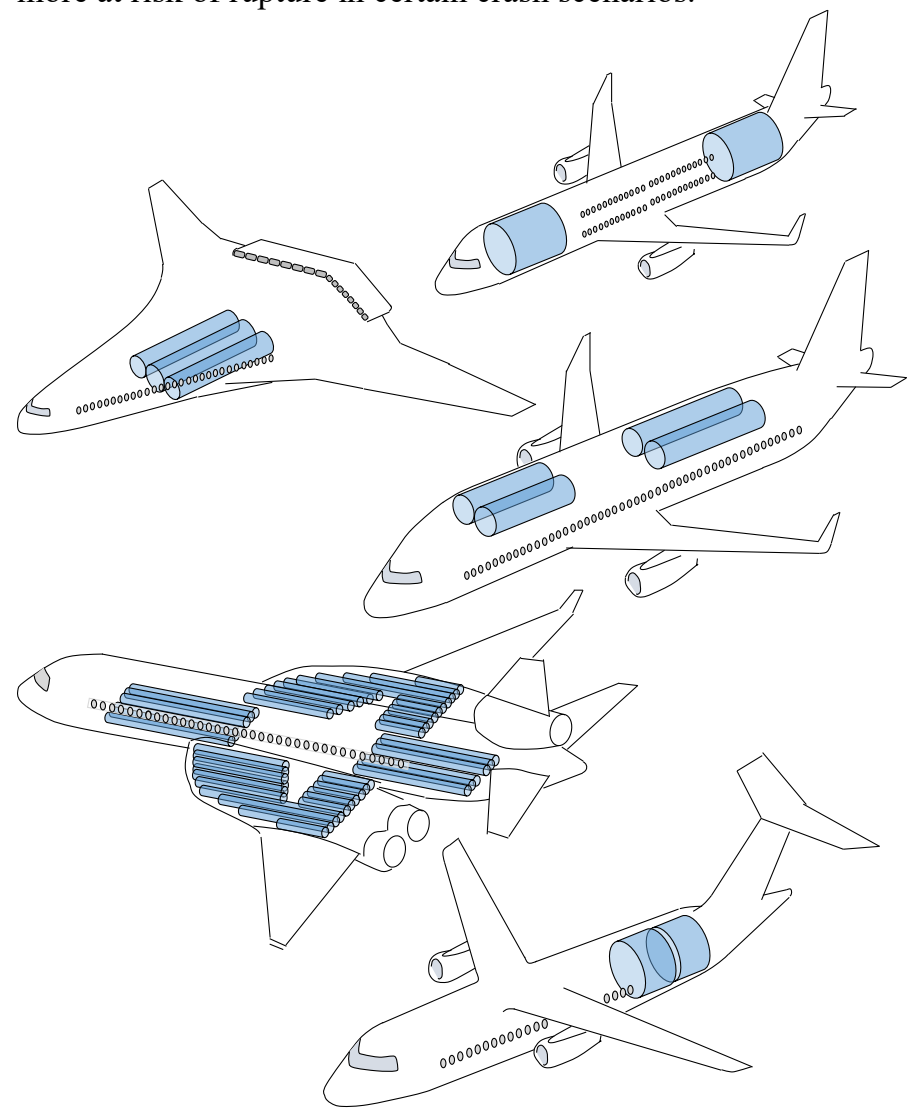

FIGURE 1: Possible fuel tank locations in various airframes

The risk of leakage from fuel systems must be addressed. The wide flammability limits of hydrogen in air argue for two lines of defence against combustible and potentially explosive mixtures accumulating inside the aircraft. One design approach is to have double-wall tanks, pipes, valves and pumps etc. By evacuating the gap between the walls and monitoring for loss of vacuum, early warning of failures could be provided. However, double walls do not guarantee zero leakage, as leaks may occur at the connections between different components. This means additional protective measures will probably be needed, such as having secondary enclosures around all credible leakage points. The secondary enclosures might be evacuated, or filled with inert gas and monitored for leaks. Possibly whole bays containing fuel system components could be protected by a dry inert gas that could also avoid icing or condensation on to cold surfaces. This gas could be generated on the aircraft. However, in less critical areas, where there is low risk of ignition, and also for podded engine installations, use of controlled ventilation flows with leak detection and fire detecting and extinguishing systems may be sufficient. Given such precautions, simpler single-wall tanks, pipes, valves etc. might be used without compromising safety.

As the aircraft will have multiple hydrogen tanks, the loss of fuel from one tank will not result in a total loss of fuel supply to the engines. Port and starboard engines would normally be fed from separate tanks or combinations of tanks. Nevertheless there needs to be provision to reconfigure the fuel supply and transfer fuel between tanks as required. For example, it may be necessary to transfer fuel between tanks when fuelling or de-fuelling the aircraft, and in order to optimise the trim of the aircraft in flight. In the event of detecting a fuel leak, it should also be possible to transfer $\mathrm{LH}_{2}$ from a leaking tank to other tanks.

Placing fuel pumps and associated shut-off valves inside the tanks should reduce the number of potential leakage paths and may simplify the pump design, as any leakage from the highpressure side would spill back into the tank. This could also avoid the need to have pipes or other components underneath the tanks, where they might be more exposed to crash damage.

Brewer describes an arrangement where each tank has two internal low-pressure rotary pumps and a design that makes it possible to exchange a pump without emptying and inerting the whole tank [6]. This level of maintainability might not be necessary if the valves and pumps can be made very simple and reliable. Piston pumps driven by linear electric motors could be very reliable and the power-electronic units to drive them could be line-replaceable units located outside of the tanks.

Fuel tanks will need to be protected against over-pressure by valves and lines to vent some $\mathrm{GH}_{2}$ overboard if necessary. However, the design of the tanks and systems for refuelling and managing fuel use on the aircraft should avoid the need to vent $\mathrm{GH}_{2}$ overboard in normal service operation.

\section{CRYOGENIC HYDROGEN PROPERTIES}

Hydrogen molecules have two isomers. The nuclear spins of the protons are somewhat aligned in orthohydrogen, whereas in parahydrogen the protons have opposite spins, giving it lower internal energy. At the normal boiling point the equilibrium composition is $99.8 \%$ parahydrogen [18], so parahydrogen properties are used in this study. It is assumed any excess orthohydrogen would be catalytically converted to parahydrogen before the $\mathrm{LH}_{2}$ would be supplied to the aircraft.

Considering hydrogen properties at $1 \mathrm{~atm}$. [19], the boiling point is $20.3 \mathrm{~K}$ and the liquid and gaseous phases have densities of 70.8 and $1.34 \mathrm{~kg} / \mathrm{m}^{3}$ respectively. For the liquid at its boiling point, the lower the pressure, the lower the temperature and the higher the density, whereas the gas always has lower density at lower pressure. However, as the liquid is always denser than the gas, storing hydrogen as a liquid is more volumetrically efficient. Cooling $\mathrm{LH}_{2}$ below $20 \mathrm{~K}$ would make it denser, but this is not an attractive option because more energy would be required to chill it. Also, without pressurisation with helium, the sub-atmospheric pressure makes it difficult to handle and risks tank implosion or the entry of air. Storing $\mathrm{LH}_{2}$ at above ambient pressure and in saturated conditions together with $\mathrm{GH}_{2}$ is a safer option. The tank contents can remain a mixture of liquid and vapour throughout 
the mission, and initially, both phases can be assumed to have homogeneous pressure and temperature.

The mixture properties of hydrogen are presented in Fig. 2 on a T-s diagram according to the data extracted from [19]. The state of the mixture can be fully defined according to two parameters. The first is either the pressure or temperature which in turn will define the densities, specific volumes, latent heat of vaporization, thermal conductivities, specific heat capacities etc. individually for the liquid and gaseous state (vertical position on the T-s diagram). The second parameter is the quality of the mixture, $x$ (vapour mass to mixture mass ratio) or alternatively the vapour to liquid volume or mass ratios which define the density, enthalpy and entropy of the mixture (horizontal position on the T-s diagram). Finally, the mixture, liquid and gaseous quantities can be calculated by providing one parameter for the mass or volume of the mixture or for the liquid or gaseous phase. These parameters are summarised in Table 1.

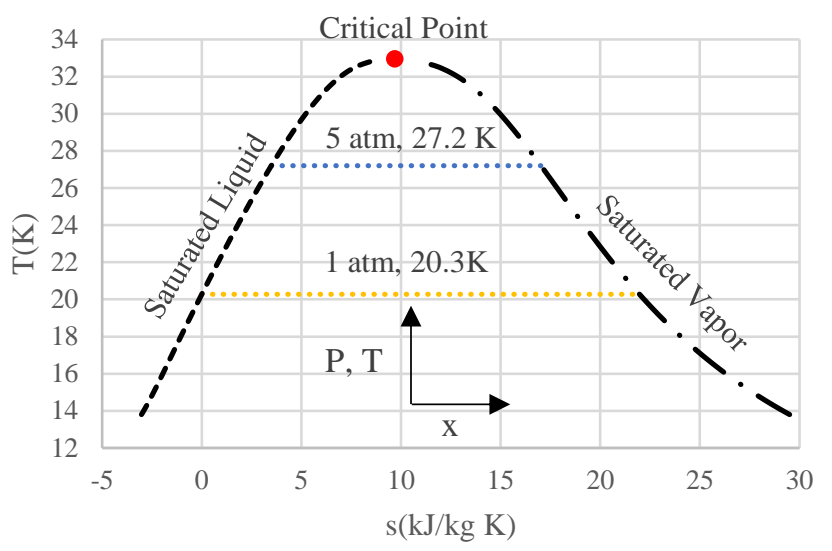

FIGURE 2: T-s diagram for liquid and gaseous hydrogen at saturated conditions

TABLE 1: hydrogen mixture properties and defining parameters

\begin{tabular}{ccc}
\hline & Properties & Parameters \\
\hline $\begin{array}{c}\text { Individual phase } \\
\text { properties }\end{array}$ & $\rho, \mathrm{h}, \mathrm{s}, \mathrm{C}_{\mathrm{P}}, \mathrm{k}, \mathrm{v}, \mathrm{h}_{\mathrm{lg}}$ & $\mathrm{P}, \mathrm{T}$ \\
Mixture properties & $\rho_{\text {mix }}, \mathrm{h}_{\text {mix }}, \mathrm{s}_{\text {mix }}$ & $\mathrm{x}, \mathrm{V}_{\mathrm{GH} 2} / \mathrm{V}_{\mathrm{LH} 2}$, \\
& $\mathrm{M}_{\mathrm{GH} 2} \mathrm{M}_{\mathrm{LH} 2}$ \\
Quantities & $\mathrm{V}_{\text {mix }}, \mathrm{V}_{\mathrm{GH} 2}, \mathrm{~V}_{\mathrm{LH} 2}$, & $\mathrm{V}_{\text {mix }}, \mathrm{V}_{\mathrm{GH} 2}, \mathrm{~V}_{\mathrm{LH} 2}$, \\
& $\mathrm{M}_{\text {mix }}, \mathrm{M}_{\mathrm{GH} 2}, \mathrm{M}_{\mathrm{LH} 2}$, & $\mathrm{M}_{\text {mix }}, \mathrm{M}_{\mathrm{GH} 2}, \mathrm{M}_{\mathrm{LH} 2}$, \\
\hline
\end{tabular}

\section{MODEL DESCRIPTION AND METHODOLOGY}

In the context of this study, cylindrical foam-insulated tanks with hemispherical cap ends are modelled. The tank comprises the wall and the insulation. The wall withstands the pressure loads developed by the pressure difference between the fuel and the ambient air and must resist embrittlement and hydrogen permeation. The insulation aims to minimise the heat leakage into the tank to avoid excessive temperature and pressure rise in typical operations.

\subsection{Geometry and mechanical sizing}

The calculation of the tank dimensions is a straightforward process using cylindrical and spherical shell geometries. For given insulation and wall thickness, the dimensions are then defined according to any two of the following parameters:

1. Total mass of the mixture stored, which according to the mixture density defines the internal volume.

2. The length of the cylindrical section.

3. The total tank length.

4. The external diameter.

The wall material needs to be chosen so that it provides a high ratio of yield strength under cryogenic conditions divided by density. Composite materials could be used, but since they are not impermeable to $\mathrm{LH}_{2}$, a liner would be required to avoid contact of the fuel with the composite wall. A NASA study [5] on an $\mathrm{LH}_{2}$ fuelled subsonic aircraft, and then Brewer [6], suggested use of Al 2219 for its manufacturability and performance at cryogenic temperatures. It is also used in this study. However, other recent studies suggest the $\mathrm{Al}-\mathrm{Cu}-\mathrm{Li}$ alloy Al 2195 might be a better choice on account of its higher strength and lower density [20].

As discussed by Barron [21], the wall thickness is determined according to the ASME Code, Section VIII by equation (1) and (2) for the cylindrical part and the hemispherical cap ends respectively. The thickness is a function of the inner tank diameter $\left(\mathrm{D}_{0}\right)$, the maximum allowable pressure difference $(\Delta \mathrm{p})$, a factor of safety for the pressure (FoS), the maximum allowable stress of the material $\left(\sigma_{a}\right)$ and the weld efficiency $\left(\mathrm{e}_{\mathrm{w}}\right)$. The mass of the wall is then calculated based on the shell geometry and the density of the material.

$$
\begin{aligned}
t_{w} & =\frac{D_{0} \times \Delta p \times F o S}{2 \sigma_{a} e_{w}-1.2 \times \Delta p \times F o S} \\
t_{w} & =\frac{D_{0} \times \Delta p \times F o S}{4 \sigma_{a} e_{w}-0.4 \times \Delta p \times F o S}
\end{aligned}
$$

\subsection{Thermal sizing \\ Heat transfer}

Several studies in the past have proposed heat transfer models for estimating the heat leak of $\mathrm{LH}_{2}$ tanks. Reynolds [7] and later on Colozza [8] estimated the heat transfer for foam insulated tanks by equalising the heat transfer by convection and radiation from the ambient air to the outer tank surface with the heat transfer via conduction through the insulation of the wall. Verstraete [10] and Winnefeld [11] included the heat transfer via convection from the liquid and gaseous phase of the hydrogen to the inner surface of the wall as shown in equation (3). Neglecting fuel convection leads to a small overestimation of the heat transfer as the thermal resistance between the fuel and the inner wall is not considered.

$$
Q_{\text {conv }, \text { LH } 2}+Q_{\text {conv }, G H 2}=Q_{\text {cond }}=Q_{\text {conv, air }}+Q_{\text {rad, air }}
$$

In this study, the heat transfer model described by equation (3) is used and is presented schematically in Fig. 3, where $T_{f}$ is the temperature of the fuel stored, $\mathrm{T}_{\mathrm{s} 1}$ the internal wall temperature, $T_{\mathrm{s} 2}$ the external wall temperature and $T_{\mathrm{amb}}$ the ambient temperature. The following assumptions are also made: 
- The hydrogen mixture is considered to be homogenous, hence temperature and pressure of the gaseous and liquid states are the same everywhere inside the tank, neglecting the effects of temperature stratification and gravity.

- Heat transfer occurs under steady-state conditions.

- Thermal and pressure expansion of the tank is neglected and therefore the tank is considered to have constant volume.

- The thermal resistance of the aluminium wall is discounted as it is orders of magnitude lower than that of the insulation.

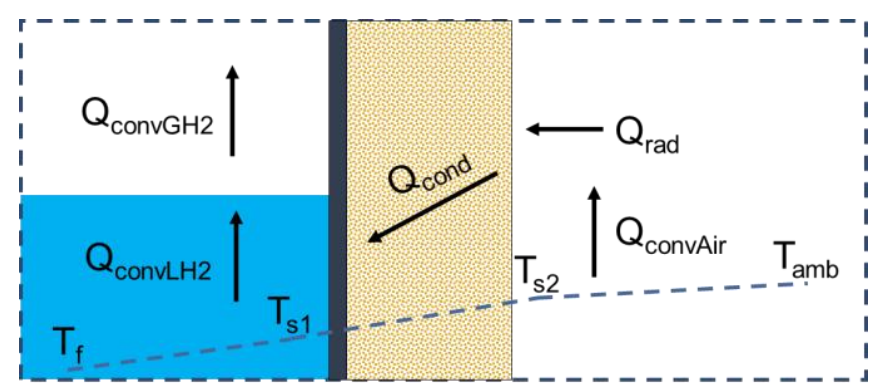

FIGURE 3: Schematic representation of the tank wall heat transfer

The fuel convective heat transfer $\left(\mathrm{Q}_{\mathrm{conv}, \mathrm{LH} 2}+\mathrm{Q}_{\mathrm{conv}, \mathrm{GH} 2}\right)$ is estimated according to the convective heat transfer coefficient, the corresponding wetted surface area of each phase and the inner wall, and fuel temperature. The convective heat transfer coefficient is a function of the thermal conductivity of each phase, as well as the Nusselt number, which for the liquid phase is estimated [22] and for the gasseous phase is set to 17 [6]. The heat transfer via conduction $\left(\mathrm{Q}_{\text {cond }}\right)$ is estimated differently for the cylindrical part and the end caps and is a function of the tank shell dimension, the thermal conductivity of the insulation, and the temperature diference between the outer and inner wall. The air convective heat transfer and radiation is calculated as in [8], differently for the cylindrical part and the cap ends, and is a function of the outer surface dimensions and the ambient air and outer wall temperature difference.

For a defined tank geometry, and fuel and ambient air temperature, $T_{\mathrm{s} 1}$ and $\mathrm{T}_{\mathrm{s} 2}$ are required for the calculation of the heat transfer terms, but are unknown, therefore their values are initialised and iterated until all parts of the heat transfer model satisfy the equilibrium of equation (3).

\section{Pressure rise estimation}

The heat transfer model described estimates the heat flux of the tank based on (among other parameters), a set of ambient and fuel temperatures. However, ambient temperature changes with altitude and fuel temperature with the heat input. Estimating the pressure variation is of primary importance as it would set the requirements for maximum allowable pressure difference $(\Delta \mathrm{p})$ which is used to size the tank wall from equations (1) and (2).

Based on the first law of thermodynamics and mass conservation, the rate of pressure rise for constant mixture volume can be calculated with equation (4), according to the energy derivative of the mixture $(\Phi)$, defined in equation (5), the volume of the mixture $(\mathrm{V})$, the heat transfer $(\mathrm{Q})$, any additional heat input (W), the mass flow rate withdrawn from the tank $\left(\mathrm{m}_{\text {out }}\right)$, the latent heat of vaporization of the mixture $\left(\mathrm{h}_{\mathrm{lg}}\right)$, the quality of the mixture withdrawn from the tank $\left(\mathrm{x}_{\text {out }}\right)$ and the densities of the liquid $\left(\rho_{\mathrm{LH} 2}\right)$ and gaseous $\left(\rho_{\mathrm{GH} 2}\right)$ phases [9] $-[11]$.

$$
\begin{gathered}
\frac{d P}{d t}=\frac{\Phi}{V}\left[Q+W-\dot{m}_{\text {out }} \cdot h_{\mathrm{lg}}\left(x_{\text {out }}+\frac{\rho_{G H 2}}{\rho_{L H 2}-\rho_{G H 2}}\right)\right] \\
\Phi=\left[\rho\left(\frac{\partial u}{\partial p}\right)_{\rho}\right]^{-1}
\end{gathered}
$$

For given heat transfer conditions, the rate of pressure rise can be increased with the use of a heater or decreased by extracting a certain mixture quantity from the tank. Considering aircraft applications, if only $\mathrm{LH}_{2}$ is withdrawn from the tank for engine use, $\mathrm{x}_{\text {out }}$ is 0 , but if $\mathrm{GH}_{2}$ is also extracted to moderate the pressure rise, $x_{\text {out }}$ is calculated based on the two flow rates. In addition, based on equation (4), the rate of pressure rise would be higher for an almost empty tank, since the lower the mixture density the higher the $\Phi[9]$. Therefore it could be preferable for the hydrogen aircraft to refuel immediately before an overnight stay at the airport. Alternatively residual $\mathrm{LH}_{2}$ could be collected in one or two tanks leaving only $\mathrm{GH}_{2}$ remaining in the others.

\subsection{Multi-point performance}

The heat transfer model discussed so far uses the following inputs:

1. Geometry and materials of the tank wall and insulation.

2. Ambient temperature.

3. $\mathrm{LH}_{2}$ and $\mathrm{GH}_{2}$ extracted from the tank.

4. The initial state of the hydrogen mixture stored.

To estimate the performance of the tank over a mission, the time is subdivided in several segments and then the heat transfer is estimated for each segment. For a sized tank and defined ambient conditions, the state of the tank contents can be calculated according to equations (6) to (8) from each previous segment. For every operating condition the volume of the mixture is constant and equal to the sized internal tank volume, equation (6). The pressure of the mixture is calculated by adding the rate of pressure rise multiplied by the duration of the previous segment and the mixture pressure of the previous segment, equation (7). The mass of the mixture is equal to the mass of the mixture of the previous segment less the mixture mass withdrawn from the tank, equation (8). Finally the amount of evaporated $\mathrm{LH}_{2}$ can be estimated based on the previous and current states of the $\mathrm{LH}_{2}$ as well as the $\mathrm{LH}_{2}$ withdrawn from the tank, as shown in equation (9).

$$
\begin{gathered}
V_{m i x, i}=\text { constant } \\
P_{m i x, i}=P_{m i x, i-1}+\left(\frac{d P}{d t}\right)_{i} t_{\text {seg }, i-1} \\
M_{m i x, i}=M_{m i x, i-1}-\left(m_{\text {engine }}+m_{\text {vent }}\right)_{i} t_{\text {seg }, i-1}
\end{gathered}
$$




$$
M_{\text {evap }, i}=M_{L H 2, i-1}-M_{L H 2, i}-m_{\text {engine }} t_{\text {seg }, i-1}
$$

\section{Model comparison with experimental data}

In this subsection the model developed is compared against two experiments found in literature involving the testing of stationary $\mathrm{LH}_{2}$ tanks. The first experiment reported by Reynolds in 1957 [23] featured a cylindrical tank and styrofoam insulation. It had internal volume of approximately $6.8 \mathrm{~m}^{3}$ and started with $\mathrm{LH}_{2}$ occupying $15.3 \%$ of the internal volume. The tank was subjected to standard day ambient conditions and no hydrogen was withdrawn from the tank. Using the model described in the multi-point performance sequence, the pressure variation of the tank contents was predicted. In Fig. 4 the experimental gauge pressure is shown together with the pressure predicted from the theoretical model. The predicted gauge pressure was however underestimated. Reynolds, using the heat transfer model described in [7] demonstrated similar levels of under-prediction.

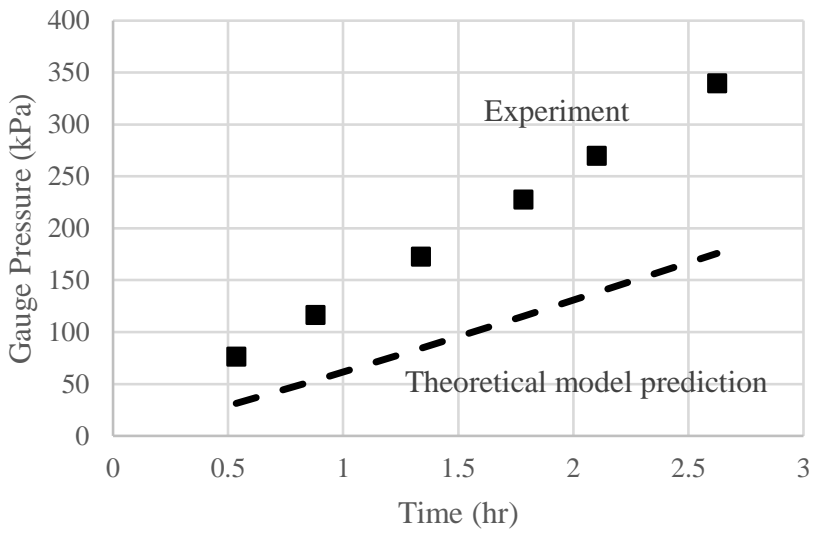

FIGURE 4: Model comparison with experimental data from [23]

In the second experiment, described by Hasan [24], an ellipsoidal tank was subjected to ambient temperatures of 350 , 280 and $80 \mathrm{~K}$ which corresponded to equivalent heat fluxes of $3.5,2.0$ and $0.35 \mathrm{~W} / \mathrm{m}^{2}$. For tests where no hydrogen was withdrawn from the tank the $\mathrm{LH}_{2}$ occupied approximately $84 \%$ of the total volume. By matching the reported parameters and conditions described in [24], the model predicted values that together with the corresponding experimental ones are presented in Fig. 5 for the two higher heat flux cases. Again similar levels of under-prediction were encountered.

In both cases, the model was predicting the heat transfer based on the homogenous mixture assumption, however, this was not the case in the actual experiments, because temperature stratification occurred. In the ellipsoidal tank experiment [24], although the $\mathrm{LH}_{2}$ showed little stratification from the bottom of the tank towards the fill level, about $2 \mathrm{~K}$, the $\mathrm{GH}_{2}$ temperature varied significantly, with a difference of $25 \mathrm{~K}$ from the fill level towards the top of the tank. As a result, the properties of the two phases differed depending on the internal vertical position in the tank, allowing a greater pressure rise than calculated for the homogenous state.

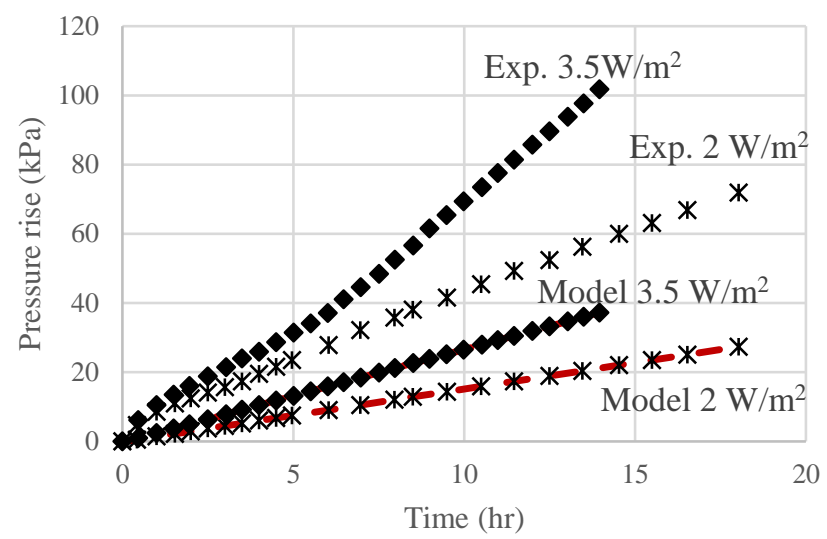

FIGURE 5: Model comparison with experimental data from [24] for heat fluxes of 3.5 and $2 \mathrm{~W} / \mathrm{m}^{2}$ for $350 \mathrm{~K}$ and $280 \mathrm{~K}$ ambient temperatures respectively.

\section{Accounting for temperature stratification and mixing}

In order to tackle the temperature stratification effect, Lin in [9] suggested multiplying the theoretical pressure rise, calculated in equation (4), by a factor of 2 , which was later also adopted in [10], [11]. In the current study, however, an average stratification heat flux factor of 2.75 will be applied, as derived from the model comparison with the experiments shown in Fig. 4 and 5. This approach is expedient as it avoids having to model the separate temperatures of the liquid and gas in the tank.

Temperature stratification can be eliminated by mixing the tank contents. Reynolds, in his experiment [23], demonstrated this by leaving the tank for a while to warm up, then shaking it externally and then repeating the process a few more times. After every mixing, the pressure of the hydrogen mixture dropped and matched that of the homogenous state predicted by the heat transfer model. Lin in [9] also proposed either continuous or repeated mixing as a way to control the pressure rise, and estimated the pressure as in equation (4) by including the mixing power in the $\mathrm{W}$ term of the equation.

Considering aircraft applications, even in the case where $\mathrm{LH}_{2}$ tanks are not equipped with internal mixing devices, there are several phases of a flight where forced external mixing can occur. For example, during accelerating or decelerating phases of the flight such as taxi, take-off, climb, descent and approach, a sloshing of the tank contents could occur to produce mixing (even if baffles are used). Conversely, during overnight stays at the airport, or in ground hold or cruise phases of the flight, where the aircraft is immobile or flies at a steady speed, temperature stratification would be expected to occur inside the tanks.

Accounting for the mixing effect, the following process is adopted. First the theoretical model pressure rise is estimated for all the examined segments. Then the heat transfer is calculated again from the beginning, only this time the stratification factor is included. If there is no mixing, the pressure of every segment is calculated from equation (7), but if mixing occurs, then the pressure is equal to the theoretical pressure estimated in the same segment. Schematically the process is shown in Fig. 6 . 


\section{ON FLIGHT APPLICATION AND OPTIMISATION}

To demonstrate the tank sizing methodology an application is performed based on the requirements of a long-range aircraft. Using Cranfield University's in house tools that combine aircraft and engine performance, the total mission on-board fuel has been calculated. The number of tanks required lies for now outside of the scope of this work as their integration needs to be carefully tailored around the airframe geometry. As such the sizing assumption is for one tank to be able to carry $5160 \mathrm{~kg}$ of $\mathrm{LH}_{2}$ and at the end of the mission there needs to be $470 \mathrm{~kg}$ of $\mathrm{LH}_{2}$ left for reserves. It is conservatively assumed that only $\mathrm{LH}_{2}$ would be usable by the engines. The flight mission is divided in several segments that will be used for the calculation, and the ambient temperature and pressure, as well as the $\mathrm{LH}_{2}$ fuel flow demand per engine, are used as inputs. The engine fuel flow rate demand against the flight time is shown in Fig. 7 normalised by its maximum value. Before take-off, a two-hour ground hold is considered with $30^{\circ} \mathrm{C}$ ambient temperature.

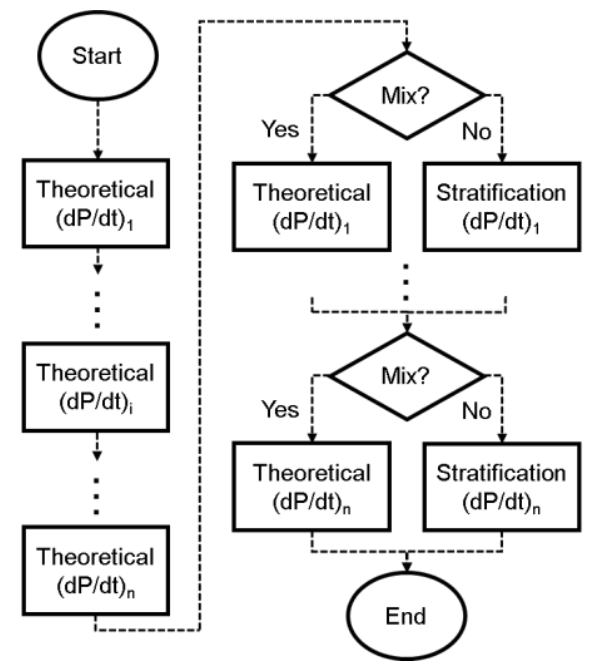

FIGURE 6: Schematic representation of the tank wall heat transfer

The tank is initially sized for the $\mathrm{LH}_{2}$ mass requirement. A minimum ullage of $3 \% \mathrm{GH}_{2}$ by volume is also considered, as discussed by Brewer [6]. The external diameter is set to $2.5 \mathrm{~m}$ and will remain a constant sizing input for all the calculations that follow. Varying the diameter will impact the heat transfer as discussed in previous studies [10], [11], however, although lighter tank designs can exist for a particular internal volume, their implementation is greatly restricted by their integration with the aircraft. The initial filling pressure is considered to be $140 \mathrm{kPa}$ and is also the same for all the calculations. Ideally, a lower pressure would allow for higher density, lower volume and reduced differential pressure levels, but considering refuelling complications, $140 \mathrm{kPa}$ is considered to be a good compromise. Lastly, the maximum allowable pressure is assumed to be $300 \mathrm{kPa}$ and the insulation is $8 \mathrm{~cm}$ of rigid polyvinylchloride closed-cell foam, with $0.0046 \mathrm{~W} / \mathrm{m}^{2} \mathrm{~K}$ thermal conductivity [8].

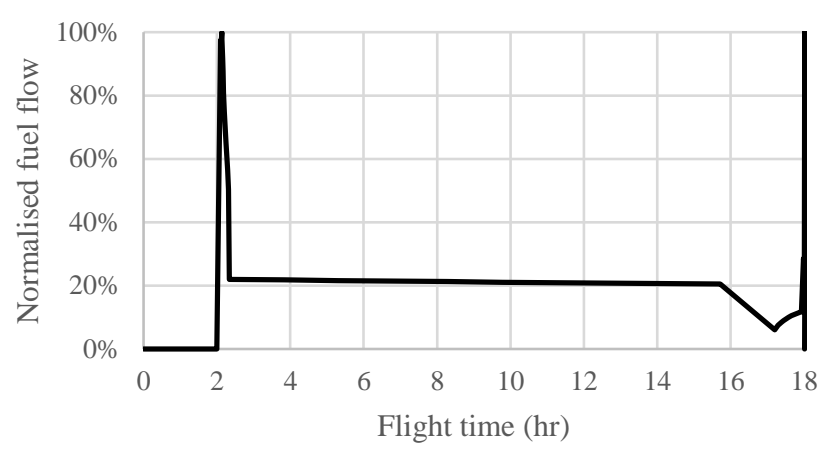

FIGURE 7: Normalised engine fuel flow demand.

\subsection{Pressure evolution \& wall optimisation}

The sized tank has an overall length of $19.1 \mathrm{~m}$ and weighs 2.85 tonnes. The tank performance throughout the mission is estimated considering that no $\mathrm{GH}_{2}$ is vented throughout the flight and that during taxi, take-off, climb, descent and landing, the tank contents are fully mixed. Fig. 8 shows the evolution of the hydrogen mixture absolute (or operating) pressure versus time for three cases: the theoretical conditions, no-mixing conditions with a stratification factor applied throughout the mission, and the case where intermittent mixing is taken into account.

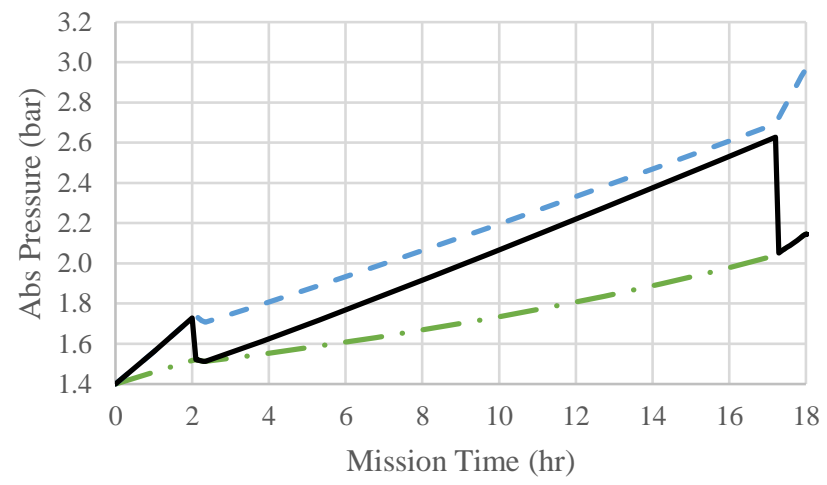

- - Theoretical - - - No mixing _ Anticipated

FIGURE 8: Absolute pressure evolution of hydrogen mixture.

At ground hold, the rate of pressure rise is relatively high since no fuel is withdrawn from the tank and the ambient temperature is high. During take-off and climb the rate of pressure rise is negative as high quantities of $\mathrm{LH}_{2}$ are consumed by the engines leading to a small absolute pressure drop for the theoretical and no mixing cases. At the same time, the pressure drops even further due to mixing, to match the theoretical predicted value. At cruise, there is an almost steady rate of pressure rise calculated, as the heat input to the tank is greater than the power extracted due to $\mathrm{LH}_{2}$ fuel removal. Finally, at descent and approach, a combination of increasing ambient temperature, low $\mathrm{LH}_{2}$ fuel consumption and low $\mathrm{LH}_{2}$ fill level leads to the highest rate of pressure rise across the whole mission, 
but only for a short amount of time. Also in the same segment, mixing provides a significant pressure drop.

Equally important as absolute pressure is consideration of the pressure difference between the fuel and the ambient air. Its evolution is shown in Fig. 9 for the three mentioned cases. After take-off, the gauge pressure is increasing due to the decrease of ambient pressure with altitude, then it steadily increases at cruise due to the absolute fuel pressure increase, and finally it drops with falling altitude through descent and landing.

From Fig. 9 it is clear that the maximum pressure difference throughout the mission of $238 \mathrm{kPa}$ is met at end of cruise. Therefore there is no need to oversize size the tank wall for more than that value. In addition, by the end of the mission, $189 \mathrm{~kg}$ of $\mathrm{LH}_{2}$ has been evaporated, leaving only $263 \mathrm{~kg}$ of $\mathrm{LH}_{2}$, equivalent to $55 \%$ of the reserve fuel, inside the tank. To compensate for that a sizing loop is established that over-sizes the tank to compensate for the evaporated fuel as well as sizing the wall according to the maximum pressure difference estimated on the mission. Fig, 10 shows schematically the iterative process. The tank is first sized according to the useable $\mathrm{LH}_{2}$ requirement. Then after calculating the tank performance for the mission, the remaining $\mathrm{LH}_{2}$ is compared with the reserves and if it does not match, the calculation is repeated and at the same time the wall is also resized according to the $\Delta \mathrm{p}$ estimated from the previous iteration. The process repeats until the remaining $\mathrm{LH}_{2}$ matches the reserve requirements and the optimum wall thickness for the insulation thickness and selected material is calculated.

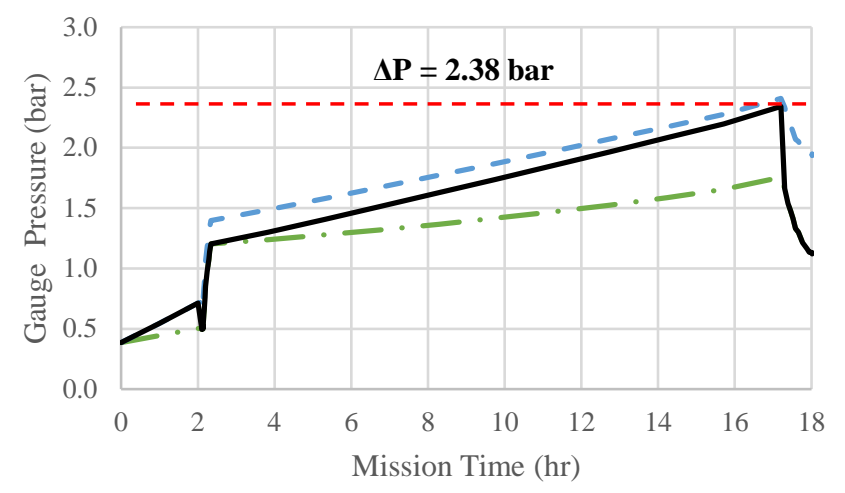

—- Theoretical - - - No mixing _ Anticipated

FIGURE 9: Gauge pressure evolution of hydrogen mixture.

By applying this process, the tank now is lighter and weighs 2.45 tonnes, has an increased capacity of $5350 \mathrm{~kg}$ of $\mathrm{LH}_{2}$ and therefore is longer with an overall length of $19.8 \mathrm{~m}$.

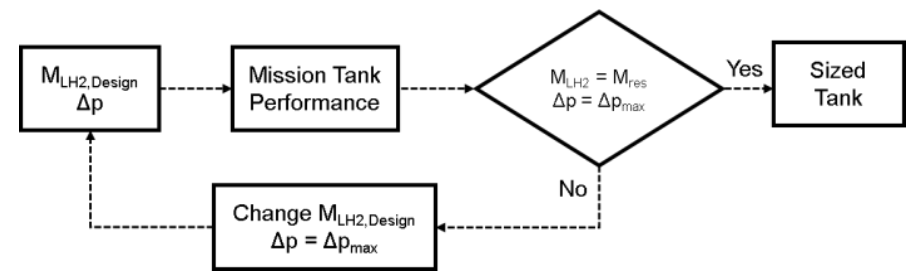

FIGURE 10: Tank sizing loop at mission level.

\subsection{Insulation thickness optimisation}

So far it has been demonstrated how to minimise the wall thickness (and tank weight) to withstand the maximum pressure difference developed in the sizing mission, and how the tank needs to be oversized to account for the evaporated $\mathrm{LH}_{2}$, for a particular insulation thickness. To showcase how the insulation thickness affects the design, a parametric study is presented where the insulation thickness is varied between 5 and $25 \mathrm{~cm}$. Fig. 11 shows how the masses of the insulation, wall, evaporated $\mathrm{LH}_{2}$ and the tank in total, vary with the insulation thickness.

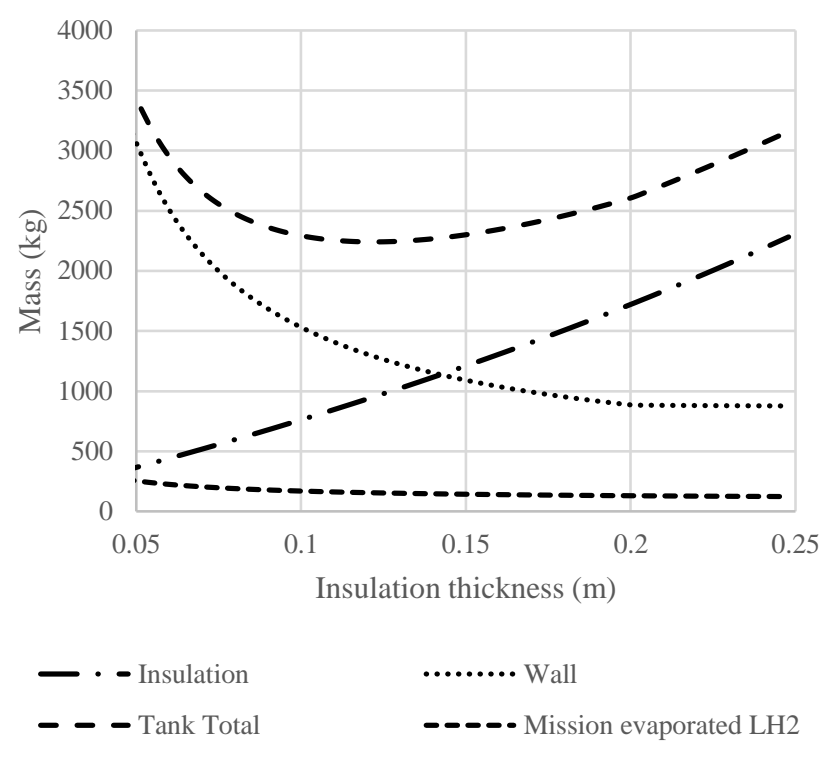

FIGURE 11: Wall, insulation, mission evaporated $\mathrm{LH}_{2}$ and total tank weight of the tank against insulation thickness.

Starting with the insulation mass, as its thickness increases its mass increases as well. However, higher insulation thickness dictates lower heat transfer and therefore a lower maximum $\Delta \mathrm{p}$ is developed, so lighter tank walls are possible. At the same time, lower the heat transfer throughout the mission means less $\mathrm{LH}_{2}$ is evaporated. This leads to an optimum point, in terms of weight, where for an insulation thickness of $12.4 \mathrm{~cm}$ the lightest tank design can be achieved, weighing 2.24 tons.

Another way to identify the best design is through the gravimetric efficiency $\left(\eta_{\text {tank }}\right)$ as defined in [11]. This is calculated as the ratio of the useful $\mathrm{LH}_{2}$ carried divided by the total $\mathrm{LH}_{2}$ stored plus the weight of the tank, as shown in equation (10).

$$
\eta_{\text {tank }}=\frac{M_{\text {usefull }}}{M_{L H 2}+M_{\text {total }}}
$$

To select the best insulation material to use, four candidates proposed in [8] are examined. The same parametric study is performed, as before, and the results are summarised in terms of tank efficiency in Fig. 12. Polyvinylchloride closed-cell foam offers the best solution, as it is at least $37 \%$ lighter than the other optimal designs and, due to lower insulation thickness, it also occupies the least space. It is also acknowledged, that although the gravimetric efficiency is affected by design considerations, 
such as tank dimensions (external diameter), filling pressure and ground hold time, varying them would still provide similar trends for the same insulation materials, and would probably dictate different optimum insulation thickness for each material.

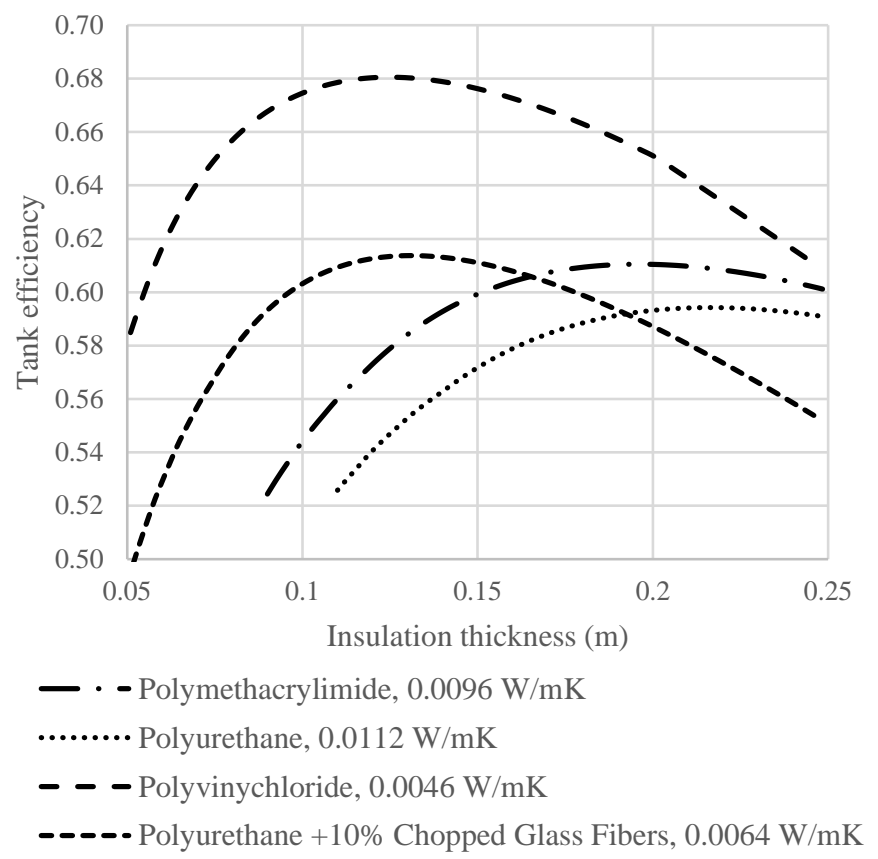

FIGURE 12: Parametric study of the insulation thickness for different insulation materials.

\section{3 $\mathrm{GH}_{2}$ extraction and venting for pressure relief}

In this section, the effect of $\mathrm{GH}_{2}$ venting on the tank design is demonstrated. For the study that will follow, it is assumed that during cruise a certain quantity of $\mathrm{GH}_{2}$ is vented overboard to limit the pressure rise.

For the design discussed that led to the pressure evolution shown in Fig. 9, the maximum pressure difference now is $123 \mathrm{kPa}$, as shown in Fig. 13. This leads to a significantly lighter design (by $48 \%$ ), but $38 \%$ more $\mathrm{LH}_{2}$ is evaporated.

A parametric study is performed using polyvinylchloride insulation for the same thickness range as before. In Fig 14 the tank efficiency is plotted against insulation thickness with and without $\mathrm{GH}_{2}$ venting at cruise and tank design parameters for the optimal designs are summarised in Table 2. The venting case provides lighter designs for low insulation thickness. Comparing the two optima, the maximum allowable pressure is $22.4 \%$ if venting during cruise is enabled, which leads to the design of a $33.6 \%$ lighter tank. With $\mathrm{GH}_{2}$ venting, although more fuel is evaporated throughout the mission, and therefore the tank needs to be sized to carry more $\mathrm{LH}_{2}$ in the first place, lower insulation thickness is required which leads to a design that occupies $7.5 \%$ less external space. To avoid pressure increase, $169 \mathrm{~kg}$ of $\mathrm{GH}_{2}$ needs to be vented from the tank. This is equivalent to a potential $380 \mathrm{~kW}$ of thermal power per tank for the whole cruise segment. The $\mathrm{GH}_{2}$ could be used in the engines or by auxiliary power units to meet aircraft secondary power requirements.

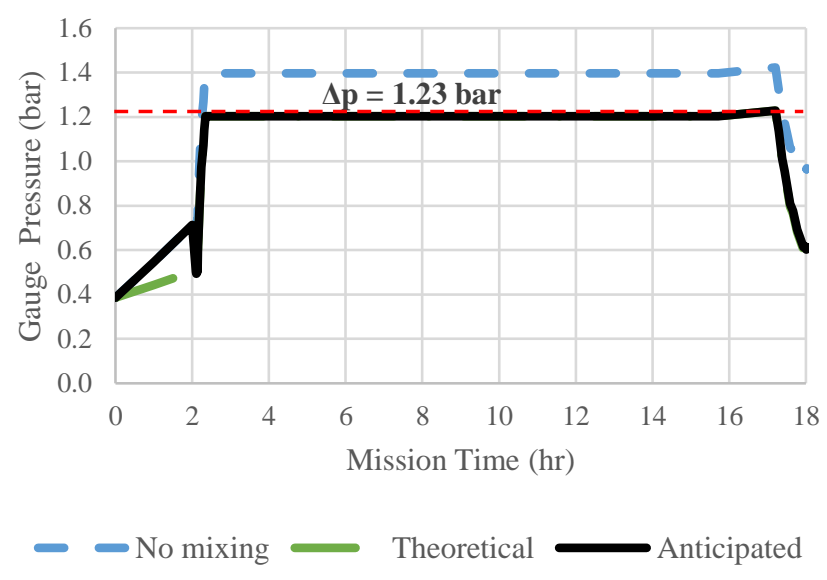

FIGURE 13: Gauge pressure evolution of hydrogen mixture, with cruise $\mathrm{GH}_{2}$ venting.

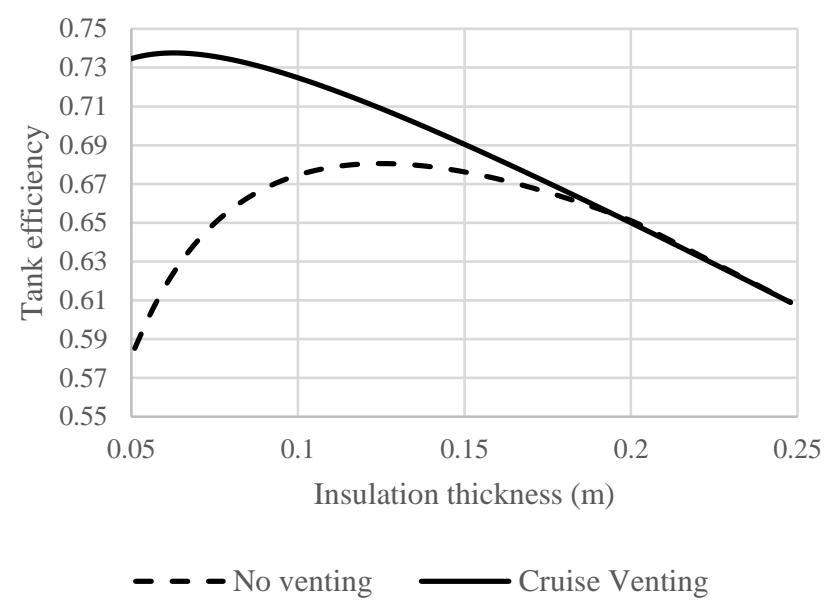

FIGURE 14: Tank gravimetric efficiency against insulation thickness, with and without cruise $\mathrm{GH}_{2}$ venting, using polyvinylchloride foam.

TABLE 2: Tank sizing optimum results

\begin{tabular}{lcccc}
\hline & Units & $\begin{array}{c}\text { No } \\
\text { venting }\end{array}$ & $\begin{array}{c}\text { Cruise } \\
\text { venting }\end{array}$ & Change \\
\hline Insulation thickness & $(\mathrm{m})$ & 0.124 & 0.063 & $-49.1 \%$ \\
Maximum allowable & $(\mathrm{kPa})$ & 162.4 & 126.1 & $-22.4 \%$ \\
pressure & $\left(\mathrm{m}^{3}\right)$ & 99.8 & 92.3 & $-7.5 \%$ \\
External volume & $(\mathrm{kg})$ & 5313 & 5484 & $+3.2 \%$ \\
$\mathrm{LH}_{2}$ stored & $(\mathrm{kg})$ & 153.4 & 323.5 & $+111 \%$ \\
Mission evaporated fuel & $(\mathrm{kg})$ & - & 169.2 & - \\
Mission vented fuel & $(\mathrm{kg})$ & 2242 & 1488 & $-33.6 \%$ \\
Total tank mass & $(-)$ & $68 \%$ & $74 \%$ & $+8.4 \%$ \\
$\eta_{\text {tank }}$ & & & & \\
\hline
\end{tabular}




\section{CONCLUSIONS}

This study has presented the methodology developed to assist design tasks in the ENABLEH2 project, and optimally size the wall and insulation thickness of a $\mathrm{LH}_{2}$ cryogenic tank for aircraft applications. The discussed model estimates the heat leak into the tank based on heat transfer principles and calculates the rate of pressure rise according to the tank geometry, insulation materials, fuel stored and ambient conditions. Considering flight operations, a methodology is established that estimates the tank performance throughout a mission, taking account of varying hydrogen conditions, ambient temperature, engine $\mathrm{LH}_{2}$ demand and temperature stratification and mixing effects. In addition, a sizing loop was introduced that oversizes the tank to compensate for the evaporated and so potentially unusable $\mathrm{LH}_{2}$ as well as optimizing the aluminium alloy wall to withstand the maximum pressure difference developed in the examined mission.

Through a parametric study for four insulation foams, the effect of different materials and increasing insulation thickness on the masses of the insulation, the wall, the tank in total, and the mission evaporated $\mathrm{LH}_{2}$ has been demonstrated. By considering the gravimetric efficiency, polyvinylchloride closed-cell foam provides the lightest solution and up to $68 \%$ efficiency for the example requirements. The effect of $\mathrm{GH}_{2}$ venting during cruise on tank sizing was also quantified, demonstrating the potential for a $33.6 \%$ reduction in empty tank weight.

Further improvements of this preliminary tank sizing model would be to better account for temperature stratification effects and how they vary throughout a flight. This could be achieved through high fidelity computational fluid dynamics simulations, where such effects can be correlated with the fill level, heat flux or dimensions. In addition, such simulations and more accurate thermal modelling, could provide a better understanding of how installation effects, like aircraft integration, piping, pumps, valves and baffles, penalise the heat transfer and how fuel sloshing throughout the different flight phases affects the pressure variation.

\section{ACKNOWLEDGEMENTS}

The ENABLEH2 project is in receipt of funding from the European Union's Horizon 2020 research and innovation programme under grant agreement No 769241. The authors confirm that the data supporting the findings of this study are available within the article.

\section{REFERENCES}

[1] Silverstein, Abe, and Eldon W. Hall. 1955. "Liquid Hydrogen as a Jet Fuel for High Altitude Aircraft." Cleveland, Ohio. NACA RM E55C28a.

[2] NASA. 2019. "NACA Research on Hydrogen for High-Altitude Aircraft." 2019. https://history.nasa.gov/SP-4404/ch6-4.htm.
[3] Sosounov, V., and V. Orlov. 1990. "Experimental Turbofan Using Liquid Hydrogen and Liquid Natural Gas as Fuel." In AIAA/SAE/ASME/ASEE 26th Joint Propulsion Conference. Orlando, Florida, USA. https://doi.org/10.2514/6.1990-2421.

[4] Mills, G. L., B. W. Buchholtz, and A. Olsen. 2012. "Design, Fabrication and Testing of a Liquid Hydrogen Fuel Tank for a Long Duration Aircraft." AIP Conference Proceedings 1434 (57): 773-80. https://doi.org/10.1063/1.4706990.

[5] Brewer, G. D., R. E. Morris, and R. H. Lange. 1975. "Study of the Application of Hydrogen Fuel To LongRange Subsonic Transport Aircraft, Volume 2." Hampton, Virginia. NASA CR-132559

[6] Brewer, Daniel. 1990. Hydrogen Aircraft Technology. CRC Press.

[7] Reynolds, T. W. 1955. "Aircraft Fuel Tank Design for Liquid Hydrogen." Washington, DC. NACA RM E55F22.

[8] Colozza, J. 2002. "Hydrogen Storage for Aircraft Applications Overview." Brook Park, Ohio. NASA / CR-2002-211867.

[9] Lin, C. S., N.T. Van Dresar, and M.M. Hasan. 1991. “A Pressure Control Analysis of Cryogenic Storage Systems." In AIAA/SAE/ASME/ASEE 27th Joint Propulsion Conference. Sacramento, CA, U.S.A. https://doi.org/10.2514/6.1991-2405.

[10] Verstraete, D., P. Hendrick, P. Pilidis, and K. Ramsden. 2010. "Hydrogen Fuel Tanks for Subsonic Transport Aircraft." International Journal of Hydrogen Energy $35 \quad$ (20): 11085-98. https://doi.org/10.1016/j.ijhydene.2010.06.060.

[11] Winnefeld, Christopher, Thomas Kadyk, Boris Bensmann, Ulrike Krewer, and Richard HankeRauschenbach. 2018. "Modelling and Designing Cryogenic Hydrogen Tanks for Future Aircraft Applications." Energies 11 (1): 1-23. https://doi.org/10.3390/en11010105.

[12] Benson, C. M., P. G. Holborn, A. M. Rolt, J. M. Ingram, and E. Alexander. 2020. "Combined Hazard Analyses To Explore the Impact of Liquid Hydrogen Fuel on the Civil Aviation Industry." In Proceedings of ASME Turbo Expo 2020 Turbomachinery Technical Conference and Exposition GT2020, 1-12. https://doi.org/https://doi.org/10.1115/GT2020-14977.

[13] Guigard, S. E., W. B. Kindzierski, and N. Harper. 2000. Heat Radiation from Flares. Canada.

[14] Benson, C. M., J. M. Ingram, P. N. Battersby, D. Mba, V. Sethi, and A. M. Rolt. 2019. "An Analysis of Civil Aviation Industry Safety Needs for the Introduction of Liquid Hydrogen Propulsion Technology." In ASME Turbo Expo 2019. Phoenix, Arizona, USA. https://doi.org/10.1115/GT2019-90453. 
[15] Sullivan, Roy M, Joseph L Palko, Robert T Tornabene, Brett A Bednarcyk, Lynn M Powers, Subodh K Mital, Lizalyn M Smith, Xiao-yen J Wang, and James E Hunter. 2006. "Engineering Analysis Studies for Preliminary Design of Lightweight Cryogenic Hydrogen Tanks in UAV Applications." Cleveland, Ohio.

[16] Rompokos, Pavlos, Andrew Rolt, Devaiah Nalianda, Askin T. Isikveren, Capucine Senné, Tomas Grönstedt, and Hamidreza Abedi. 2020. "Synergistic Technology Combinations for Future Commercial Aircraft Using Liquid Hydrogen." In Proceedings of the ASME 2020 International Mechanical Engineering Congress and Exposition GT2020. Virtual, Online. https://doi.org/10.1115/GT2020-15694.

[17] Gomez, Arturo, and Howard Smith. 2019. "Liquid Hydrogen Fuel Tanks for Commercial Aviation: Structural Sizing and Stress Analysis." Aerospace Science and Technology 95. https://doi.org/10.1016/j.ast.2019.105438.

[18] Balepin, Vladimir V., Makoto Yoshida, and Kenjiro Kamijo. 1994. "Rocket Based Combined Cycles for Single Stage Rocket.” In SAE Technical Papers. SAE International. https://doi.org/10.4271/941166.

[19] NIST. 2020. "Thermophysical Properties of Fluid Systems." 2020. https://webbook.nist.gov/chemistry/fluid/.
[20] Nayan, Niraj, S V S Narayana Murty, Abhay K Jha, Bhanu Pant, S C Sharma, Koshy M George, and G V S Sastry. 2014. "Mechanical Properties of AluminiumCopper-Lithium Alloy AA2195 at Cryogenic Temperatures." Materials \& Design 58: 445-50. https://doi.org/10.1016/j.matdes.2014.02.024.

[21] Barron, R. F. 1985. Cryogenic Systems. Edited by Oxford University Press. 2nd ed. New York: Oxford University Press.

[22] Hochstein, J. I., H. C. Ji, and J. C. Aydelott. 1986. "Effect of Subcooling on the On-Orbit Pressurization Rate of Cryogenic Propellant Tankage." In AIAAIASME 4th Joint Thermophysics and Heat Transfer Conference. Boston Massachusetts. https://doi.org/10.2514/6.1986-1253.

[23] Reynolds, Thaine, and Solomon Weiss. 1957. "Experimental Study of Foam-Insulated Liquefied-Gas Tanks." Cleveland, Ohio. https://doi.org/NACA RM E56K08a.

[24] Hasan, M. M., C. S. Lin, and N. T. Van Dresar. 1991. "Self-Pressurization of a Flightweight Liquid Hydrogen Storage Tank Subjected to Low Heat Flux." Cleveland, Ohio. NASA TM -103804. 